\title{
Prevalence of 'one and done' in adenoma detection rates: results from the New Hampshire Colonoscopy Registry
}

\section{(ㄷ)(1) $\ominus$}

Authors

Stacey A. Fedewa', Joseph C. Anderson ${ }^{2,3}$, Christina M. Robinson ${ }^{4}$, Julie E. Weiss ${ }^{5}$, Robert A. Smith ${ }^{6}$, Rebecca L. Siegel ${ }^{1}$, Ahmedin Jemal' ${ }^{1}$, Lynn F. Butterly ${ }^{2,4}$

Institutions

1 Department of Intramural Research, American Cancer Society, Atlanta, Georgia, United States

2 Geisel School of Medicine at Dartmouth, Lebanon, New Hampshire, United States

3 Department of Veterans Affairs Medical Center, White River Junction, Vermont, United States

4 Section of Gastroenterology, Dartmouth Hitchcock Medical Center, Lebanon, New Hampshire, United States

5 Department of Biomedical Data Science, Geisel School of Medicine at Dartmouth, Hanover, New Hampshire, United States

6 Department of Cancer Control, American Cancer Society, Atlanta, Georgia, United States

submitted 26.10.2018

accepted after revision 25.2.2019

\section{Bibliography}

DOI https://doi.org/10.1055/a-0895-5410 |

Endoscopy International Open 2019; 07: E1344-E1354

(c) Georg Thieme Verlag KG Stuttgart · New York

eISSN 2196-9736

Corresponding author

Stacey Fedewa, 250 Williams Street, Atlanta, GA 30303

Fax: (404) 321-4669

Stacey.fedewa@cancer.org

\section{ABSTRACT}

Background and study aims Adenoma detection rate (ADR), the proportion of an endoscopist's screening colonoscopies in which at least one adenoma is found, is an established quality metric. Several publications have suggested that a technique referred to as "one and done," where less attention is paid to additional polyp detection following discovery of one likely adenoma, may be occurring [1 3]. To investigate whether this practice occurs and provide additional context to the significance of ADR, we examined ADR by single and multiple adenomas in the statewide New Hampshire Colonoscopy Registry (NHCR).

Patients and methods A total of 25,324 NHCR patients receiving screening colonoscopies between 2009 and 2014 by 69 endoscopists were analyzed. ADR was dichotomized into high ( $\geq 20 \%$ ) and low ( $<20 \%$ ) based on 2006 recommended targets in place during the time of the study. ADR-plus (the average number of adenomas in colonoscopies with $>1$ adenoma) was dichotomized at mean values into high $(\geq 1.5)$ and low $(<1.5)$. As suggested by others, a high ADR but low ADR-plus was used to indicate the "one and done" approach.

Results Among endoscopists with an $A D R \geq 20 \%$, only 5 (7.2\%) had low ADR-plus values and were classified as "one and done." Results for serrated polyp detection were similar. ADR and ADR-plus decreased monotonically with increasing years since residency $(P$ values for trend $A D R=$ 0.02 ; ADR-plus $=0.003$ ) after adjusting for patient risk factors.

Conclusion "One and done" infrequently occurred among endoscopists with high ADR in a large statewide registry. The need to replace ADR with other polyp detection metrics (such as ADR-plus) to accurately ascertain performance quality is not supported by these findings.

\section{Introduction}

Colonoscopy is the most commonly used colorectal cancer (CRC) screening test in the United States[4]. It can detect and remove precancerous adenomas and other polyps, thereby reducing risk of CRC, the third most common cancer among men and women in the United States, respectively [5]. Quality indicators for colonoscopy have been developed and recommended to optimize the test's benefits and reduce interval CRC, cancers that develop after a negative colonoscopy but before the next recommended test [6]. Adenoma detection rate (ADR), measured as the proportion of an endoscopist's screen- 
ing colonoscopies in which at least one adenomatous polyp (adenoma) was removed, is the primary quality indicator. The American Society for Gastrointestinal Endoscopy (ASGE) initially recommended that endoscopists achieve an ADR of $20 \%$ overall (for men and women combined) in 2006 [7]. This target was updated to $25 \%$ in 2015 based on contemporary evidence that interval CRC risk was significantly greater among people receiving their colonoscopies from endoscopists below this threshold [8-10].

Several studies have proposed that ADR is a necessary, but possibly not a sufficient metric of quality in that it may not fully capture an endoscopist's performance in clinical practice [1, 11]. Authors have expressed concern that some endoscopists, despite achieving a high ADR, may not be as careful in examining the mucosa after resecting a polyp that is likely to be an adenoma, a practice referred to as "one and done" $[1-3,12]$. Another possibility is that, knowing that a particular resected polyp requires a shorter follow-up (for example a polyp larger than 1 centimeter requiring a 3 -year surveillance interval), endoscopists may be less meticulous about searching for smaller adenomas throughout the remainder of that exam. Thus, because it is possible that an endoscopist could have an adequate or high ADR but not be vigilant about resecting all of the adenomas in the patient's colon, some authors have suggested a focus on alternate quality measures, for example, ADR metrics that assess the number of adenomas per exam, rather than the ADR itself.

The New Hampshire Colonoscopy Registry (NHCR) is an established, statewide, population-based registry that has been collecting comprehensive colonoscopy data for over a decade. We investigated the prevalence of "one and done" within the NHCR to assess the concerns regarding use of ADR to assess quality, and the potential need to increase focus on additional ADR metrics. We also examined additional measures that may provide context to the ADR, and assessed the influence of endoscopist characteristics on these measures to better understand clinical performance.

\section{Patients and methods}

\section{Data source and study population}

The NHCR is a population-based registry, established in 2004, that collects data from consenting patients and endoscopists at participating hospitals, ambulatory surgery centers, and community endoscopy practices located across the state of New Hampshire [13]. Details about the NHCR have been previously described [13]. Briefly, data are collected from patient questionnaires and colonoscopy procedure forms which are subsequently linked to pathology reports [14]. Pathology reports are requested from pathology labs and abstracted by trained NHCR staff in consultation with an expert gastrointestinal pathologist when needed, with polyp-level pathology results linked to corresponding findings on the colonoscopy procedure form. This study was approved by the Committee for the Protection of Human Subjects at Dartmouth College (Study Number 15834) and other relevant human subjects review boards.

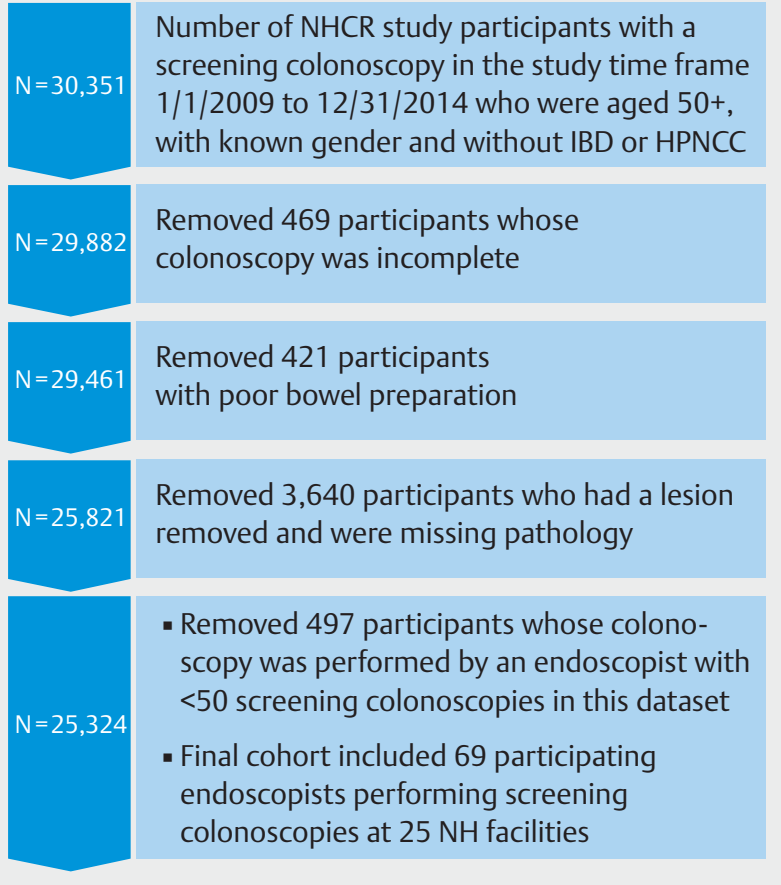

- Fig. 1 Cohort diagram of New Hampshire Colonoscopy Registry participants with a screening colonoscopy, 2009-2014.

Patients $\geq 50$ years who received a screening colonoscopy (no symptoms and no personal history of polyps or CRC) were selected ( $\triangleright$ Fig.1). Colonoscopies that were incomplete or missing completion status $(n=469)$, those with poor bowel preparation $(n=421)$, or those in which lesions were removed but pathology data were missing at the time of the analysis $(n=3,640)$ were excluded. Patients who underwent colonoscopy by an endoscopist with fewer than 50 screening colonoscopies in the NHCR dataset $(n=497)$ were also excluded. The analytic study population included 25,324 patients who received colonoscopies from 69 endoscopists across 25 endoscopy facilities.

\section{Outcome measures}

Five quality metrics related to polyp detection were evaluated and defined in > Supplemental Table 1: ADR, ADR-plus, serrated and adenoma detection rate (SADR), SADR-plus, and polyp detection rate (PDR). All metrics were computed among screening colonoscopies only. ADR was calculated as the number of an endoscopist's colonoscopies in which at least one adenoma was detected, divided by the number of screening colonoscopies performed by that endoscopist. Approximately $37 \%$ to $47 \%$ of exams with adenomas present have been found to have more than one adenoma [1]. Endoscopists with high ADRs, who are presumably performing high-quality exams, could be expected to detect a relatively high number of adenomas during colonoscopies; thus, ADR-plus (the average number of adenomas in colonoscopies with $>1$ adenoma) was investigated [1]. 
The serrated polyp detection rate is a proposed measure of quality; these lesions may be difficult to detect and are related to interval CRC development $[15,16]$. Because careful inspection of the colon may lead to a higher detection rate for serrated polyps as well as for adenomas, to credit endoscopists who detect and remove clinically important lesions other than adenomas, we used a measure designed to incorporate both types of polyps (SADR). SADR and SADR-plus were calculated like ADR and ADR-plus but included exams with clinically significant serrated polyps (CSSPs) as well as adenomas in the numerator. CSSPs were defined as any sessile serrated adenoma/ polyp or traditional serrated adenoma, or any hyperplastic polyp $(\mathrm{HP})>1 \mathrm{~cm}$ anywhere in the colon or an $\mathrm{HP}>5 \mathrm{~mm}$ in the proximal colon (thus excluding diminutive rectosigmoid HPs thought to have no malignant potential).

We also evaluated PDR, the proportion of screening colonoscopies in which at least one polyp is detected. The advantage of calculating PDR is that it is measured without the need for obtaining pathology. However, PDR has been described as potentially susceptible to "gaming" by endoscopists who might remove a single polyp to ensure a high PDR and then consider the colonoscopy complete [10]. ADR is less vulnerable to manipulation, because the specific pathology of the polyps must be confirmed; furthermore, use of ADR may encourage greater emphasis on removing all polyps because specific pathology may not be discernible at time of colonoscopy.

\section{Independent factors}

Patient factors included gender (male, female), age at colonoscopy $(50-54,55-59,60-64,65-70,70-74, \geq 75)$, race/ethnicity (non-white, white) and educational attainment ( $\leq$ high school, some college/college). First-degree family history of CRC (no, yes), smoking (never, former, and current) as well body-mass index (BMI) groups (underweight/normal, overweight, obese class I, obese class II and III) were analyzed.

Endoscopist factors included gender (male, female) and specialty (gastroenterology, surgery). Endoscopist age and the number of years since residency $(1-7,8-14,15-19,20-28$, 229 ) were calculated based on an assigned reference date, which was defined as the date of the endoscopist's first screening colonoscopy performed in the study period.

\section{Statistical analysis}

Differences in quality metrics by patient and endoscopist characteristics were assessed using Chi-square and Fishers exact tests $(\alpha=0.05)$. Box and quartile-quartile plots were used to assess if quality metrics were normally distributed; all measures were normally distributed (data not shown). Correlations between quality metrics were assessed using Spearman rank coefficients.

To determine which endoscopist factors may be associated with ADR and ADR-plus, a multivariable generalized linear model was conducted separately for each outcome and endoscopist factor after accounting for the proportion of an endoscopist's patients who were obese, current smokers, former smokers, males, and $\geq 65$ years $[17,18]$.
We applied a visualization technique developed by Wang and colleagues where endoscopists' ADR and ADR-plus values were plotted against one another [1]. Plots were separated into four main quadrants of high/low ADR and ADR-plus values. ADR was dichotomized into high ( $\geq 20 \%)$ and low $(<20 \%)$ based on the 2006 ASGE target, which was in place during the study period [7]. The mean ADR-plus value in our study population (1.5) was used to create high $(\geq 1.5)$ and low $(<1.5)$ ADR-plus groups, as there are no published targets for this metric. A high ADR but low ADR-plus could possibly suggest a "one and done" approach [1]. We also assessed results using ADR defined as high ( $\geq 25 \%$ ) and low (<25\%) based on the 2015 ASGE ADR target of $25 \%$ [10].

\section{Results}

Among the study cohort ( $N=25,324$ patients who had a complete screening colonoscopy with adequate bowel preparation), median patient age at colonoscopy was 56 years and $43.3 \%$ were male. Most colonoscopy recipients were white (95.8\%), had some college education (77.7\%), did not report a family history of CRC (79.9\%), and were overweight or obese (70.7\%) ( Table 1$)$. More than one-third of patients (38.2\%) were former smokers and $8.3 \%$ reported as current smokers. At least one adenoma was detected in $23.2 \%$ of patients; this proportion was greater in males than in females, in smokers compared to non-smokers, and increased with age and higher BMI category ( $\triangleright$ Table 1 ). The number of adenomas and CSSP detection also varied by these factors.

Characteristics and associations with quality metrics of the 69 endoscopists analyzed are shown in > Table 2. Most physicians were male (85.5\%) and gastroenterologists (75.0\%). The median endoscopist age and years since residency were 50 and 17.5 years, respectively. The median ADR was 22.9 (interquartile range: $15.9-27$ ) and the median ADR-plus was 1.5 (interquartile range: $1.4-1.7$ ) ( Supplemental Table 2). Mean ADR and ADR-plus were nearly identical to these medians, owing to their normal distribution, at 22.1 and 1.5 , respectively. ADR was strongly and significantly correlated with PDR $(p=0.82, P$ $<0.001)$ and SADR $(p=0.98, P<0.001)$ ( $\triangleright$ Table 3$)$. The correlation between ADR and ADR-plus ( $p=0.65, P<0.001)$, and SADRplus $(p=0.62, P<0.001)$ was only moderate.

We observed an inverse relationship between endoscopist age (and correspondingly the number of years since residency), and both ADR and ADR-plus ( $\triangleright$ Table 2 ). For example, the average ADRs for endoscopists completing residency within 1 to 7 years and $\geq 20$ years prior to the reference date were $27.7 \%$ and $16.6 \%$, respectively. Gastroenterologists had higher ADR, SADR, and PDR values than surgeons, but similar ADR-plus values were observed ( $\triangleright$ Table 2 ).

In analyses examining the relationship of each endoscopist characteristic with ADR and ADR-plus values adjusted for patient risk factors (smoking status, obesity, sex and age), results were similar to results that did not account for these patient risk factors. ADR decreased monotonically with increasing endoscopist age ( $P$ for trend $=0.05$ ) and years since residency ( $P$ for trend $=0.02$ ). Inverse associations between these factors 
- Table 1 Colonoscopy quality metrics by patient characteristics, NHCR 2009-20141.

\begin{tabular}{|c|c|c|c|c|}
\hline & Total & $\geq 1$ adenoma & No. of adenomas & $\geq 1$ CSSP \\
\hline Participants characteristics & $\mathrm{N}(\mathrm{Col} \%)$ & N (Row \%) & Mean (SD) & N (Row \%) \\
\hline Total & 25,324 & $5,862(23.2)$ & & $1,244(5.0)$ \\
\hline Age at colonoscopy (years) & & $P<0.0001$ & $P<0.0001$ & $P=0.02$ \\
\hline $50-54$ & $11,036(43.6)$ & $2,312(21.0)$ & $1.49(1.0)$ & $540(4.9)$ \\
\hline $55-59$ & $4,465(17.6)$ & $1,050(23.5)$ & $1.56(1.1)$ & $245(5.5)$ \\
\hline $60-64$ & $4,268(16.8)$ & $1,044(24.5)$ & $1.63(1.2)$ & $204(4.8)$ \\
\hline $65-69$ & $3,014(11.9)$ & $778(25.8)$ & $1.61(1.1)$ & $163(5.5)$ \\
\hline $70-74$ & $1,461(5.9)$ & 401 (26.9) & $1.84(1.3)$ & $56(3.8)$ \\
\hline$\geq 75$ & $1,050(4.2)$ & $277(26.4)$ & $1.73(1.4)$ & $36(3.5)$ \\
\hline Year of colonoscopy & & $P<0.0001$ & $P<0.0001$ & $P<0.0001$ \\
\hline 2009 & $1,825(7.2)$ & $385(21.1)$ & $1.45(1.0)$ & $67(3.7)$ \\
\hline 2010 & $3,481(13.7)$ & $790(22.7)$ & $1.50(1.0)$ & $152(4.4)$ \\
\hline 2011 & $4,822(19.0)$ & $992(20.6)$ & $1.54(1.0)$ & $198(4.1)$ \\
\hline 2012 & $6,820(26.9)$ & $1,533(22.5)$ & $1.57(1.1)$ & $314(4.7)$ \\
\hline 2013 & $6,538(25.8)$ & $1,615(24.7)$ & $1.61(1.2)$ & $349(5.4)$ \\
\hline 2014 & $1,838(7.3)$ & $547(29.8)$ & $1.80(1.2)$ & $164(9.1)$ \\
\hline Gender & & $P<0.0001$ & $P<0.0001$ & $P=0.001$ \\
\hline Female & $14,364(56.7)$ & $2,614(18.2)$ & $1.43(0.9)$ & $652(4.6)$ \\
\hline Male & $10,960(43.3)$ & $3,248(29.6)$ & $1.70(1.2)$ & $592(5.5)$ \\
\hline Race & & $P=0.77$ & $P=0.24$ & $P=0.40$ \\
\hline White & $23,390(95.8)$ & $5,414(23.2)$ & $1.57(1.1)$ & $1,153(5.0)$ \\
\hline Non-white & $1,032(4.2)$ & $243(23.6)$ & $1.65(1.2)$ & $45(4.4)$ \\
\hline Education & & $P<0.0001$ & $P=0.17$ & $P=0.02$ \\
\hline Some college/college & $18,886(77.7)$ & $4,274(22.6)$ & $1.56(1.1)$ & $893(4.8)$ \\
\hline$\leq$ High school & $5,418(22.3)$ & $1,373(25.3)$ & $1.61(1.1)$ & $296(5.5)$ \\
\hline Family history of CRC (first degree) & & $P=0.29$ & $P=0.28$ & $P=0.79$ \\
\hline No & $19,924(79.9)$ & $4,571(23.4)$ & $1.59(1.1)$ & $961(5.0)$ \\
\hline Yes & $4,909(20.1)$ & $1,114(22.7)$ & $1.55(1.0)$ & $247(5.1)$ \\
\hline BMI $\left(\mathbf{k g} / \mathrm{m}^{2}\right)$ & & $P<0.0001$ & $P<0.0001$ & $P<0.0001$ \\
\hline Underweight/Normal $<25$ & $7,093(29.3)$ & $1,338(18.9)$ & $1.45(0.9)$ & 277 (3.9) \\
\hline Overweight 25 to $<30$ & $9,035(37.3)$ & $2,118(23.4)$ & $1.54(1.0)$ & $464(5.2)$ \\
\hline Obese 30 to $<35$ & $5,096(21.0)$ & $1,359(26.7)$ & $1.67(1.2)$ & $290(5.8)$ \\
\hline Obese (Class II + III) $\geq 35$ & $2,994(12.4)$ & $792(26.5)$ & $1.69(1.2)$ & $161(5.4)$ \\
\hline Smoking Status & & $P<0.0001$ & $P<0.0001$ & $P<0.0001$ \\
\hline Never & $13,067(53.5)$ & $2,764(21.2)$ & $1.51(1.0)$ & $556(4.3)$ \\
\hline Former & $9,321(38.2)$ & $2,227(23.9)$ & $1.61(1.1)$ & 450 (4.9) \\
\hline Current & $2,024(8.3)$ & $683(33.8)$ & $1.70(1.2)$ & $199(10.0)$ \\
\hline
\end{tabular}


- Table 2 Colonoscopy quality metrics by endoscopist characteristics, NHCR 2009-2014.

\begin{tabular}{|c|c|c|c|c|c|c|c|}
\hline & \multicolumn{2}{|c|}{ Total } & \multirow{2}{*}{$\begin{array}{l}\text { ADR } \\
\text { P value }\end{array}$} & \multirow{2}{*}{$\begin{array}{l}\text { ADR-plus } \\
\text { P value }\end{array}$} & \multirow{2}{*}{$\begin{array}{l}\text { SADR } \\
P \text { value }\end{array}$} & \multirow{2}{*}{$\begin{array}{l}\text { SADR-plus } \\
\text { P value }\end{array}$} & \multirow{2}{*}{$\begin{array}{l}\text { PDR } \\
P \text { value }\end{array}$} \\
\hline & & & & & & & \\
\hline Endoscopist characteristics ${ }^{1}$ & n & $\%$ & Mean (SD) & Mean (SD) & Mean (SD) & Mean (SD) & Mean (SD) \\
\hline Total & & & $22.1(9.1)$ & $1.5(0.2)$ & $26.9(11.4)$ & $1.5(0.2)$ & $39.2(16.4)$ \\
\hline $\begin{array}{l}\text { age in years } \\
\text { (Median = 50, IQR: } 43-58 \text { ) }\end{array}$ & & & 0.01 & 0.04 & 0.01 & 0.25 & 0.01 \\
\hline$<40$ & 11 & 16.7 & $28.5(9.0)$ & $1.7(0.2)$ & $35.3(12.6)$ & $1.6(0.2)$ & $52.4(17.0)$ \\
\hline $40-59$ & 41 & 62.1 & $21.6(8.4)$ & $1.5(0.2)$ & $26.3(10.9)$ & $1.5(0.2)$ & $36.7(13.8)$ \\
\hline$\geq 60$ & 14 & 21.2 & $17.9(9.5)$ & $1.4(0.3)$ & $21.2(10.5)$ & $1.5(0.2)$ & $34.6(16.8)$ \\
\hline Gender & & & 0.60 & 0.84 & 0.65 & 0.93 & 0.88 \\
\hline Male & 59 & 85.5 & $20.7(8.7)$ & $1.5(0.2)$ & $25.3(10.6)$ & $1.5(0.2)$ & $39.9(21.6)$ \\
\hline Female & 10 & 14.5 & $22.3(9.2)$ & $1.4(0.2)$ & $27.1(11.6)$ & $1.5(0.2)$ & $39.1(15.5)$ \\
\hline Endoscopy Specialty & & & $<0.0001$ & 0.22 & 0.0002 & 0.60 & 0.001 \\
\hline Gastroenterology & 51 & 75.0 & $24.5(8.0)$ & $1.5(0.2)$ & $29.8(10.4)$ & $1.5(0.2)$ & $43.0(14.7)$ \\
\hline Surgery & 17 & 25.0 & $14.8(8.7)$ & $1.5(0.2)$ & $18.6(10.5)$ & $1.5(0.2)$ & 28.4 (16.9) \\
\hline $\begin{array}{l}\text { No. years since residency } \\
\text { (Median = } 17 \text { IQR: } 10.5-26.5 \text { ) }\end{array}$ & & & 0.03 & 0.01 & 0.02 & 0.03 & 0.03 \\
\hline $1-7$ & 11 & 16.2 & $27.7(8.0)$ & $1.7(0.1)$ & $34.1(10.5)$ & $1.6(0.1)$ & $52.7(18.0)$ \\
\hline $8-14$ & 17 & 25.0 & $22.8(8.5)$ & $1.5(0.2)$ & $28.6(11.5)$ & $1.5(0.2)$ & $39.9(14.3)$ \\
\hline $15-19$ & 11 & 16.2 & $24.1(10.6)$ & $1.6(0.3)$ & $28.8(13.3)$ & $1.6(0.2)$ & $37.7(16.6)$ \\
\hline $20-28$ & 15 & 22.1 & $20.8(7.1)$ & $1.4(0.3)$ & $25.0(8.7)$ & $1.4(0.2)$ & 36.4 (13.9) \\
\hline$\geq 29$ & 14 & 20.6 & $16.6(9.4)$ & $1.4(0.2)$ & $19.7(10.5$ & $1.3(0.2)$ & $32.6(16.1)$ \\
\hline
\end{tabular}

NHCR, New Hampshire Colonoscopy Registry; IQR, interquartile range; ADR, adenoma detection rate; ADR-plus, adenoma detection rate-plus; SADR, serrated and adenoma polyp detection rate; SADR-plus, serrated and adenoma polyp detection rate-plus; PDR, polyp detection rate

1 Missing (N): age (3); specialty (1); number of years since residency (1)

- Table 3 Correlations between measures of colonoscopy quality, NHCR 2009-2014.

\begin{tabular}{|c|c|c|c|c|c|c|}
\hline & & ADR & ADR-plus & SADR & SADR-plus & PDR \\
\hline \multirow[t]{2}{*}{ ADR } & $\mathrm{p}$ & 1.00 & 0.65 & 0.98 & 0.58 & 0.82 \\
\hline & $P$ value & - & $<.0001$ & $<.0001$ & $<.0001$ & $<.0001$ \\
\hline \multirow[t]{2}{*}{ ADR-plus } & $\mathrm{p}$ & 0.65 & 1.00 & 0.66 & 0.93 & 0.49 \\
\hline & $P$ value & $<.0001$ & - & $<.0001$ & $<.0001$ & $<.0001$ \\
\hline \multirow[t]{2}{*}{ SADR } & $\mathrm{p}$ & 0.98 & 0.66 & 1.00 & 0.57 & 0.82 \\
\hline & $P$ value & $<.0001$ & $<.0001$ & - & $<.0001$ & $<.0001$ \\
\hline \multirow[t]{2}{*}{ SADR-plus } & $\mathrm{p}$ & 0.58 & 0.93 & 0.57 & 1.00 & 0.44 \\
\hline & $P$ value & $<.0001$ & $<.0001$ & $<.0001$ & - & $<.0001$ \\
\hline \multirow[t]{2}{*}{ PDR } & p & 0.82 & 0.49 & 0.82 & 0.44 & 1.00 \\
\hline & $P$ value & $<.0001$ & $<.0001$ & $<.0001$ & $<.0001$ & - \\
\hline
\end{tabular}

NHCR, New Hampshire Colonoscopy Registry; ADR, adenoma detection rate; ADR-plus, adenoma detection rate-plus; SADR, serrated and adenoma polyp detection rate; SADR-plus, serrated and adenoma polyp detection rate-plus; PDR, polyp detection rate.

$\rho=$ Spearman Rank correlation coefficient 


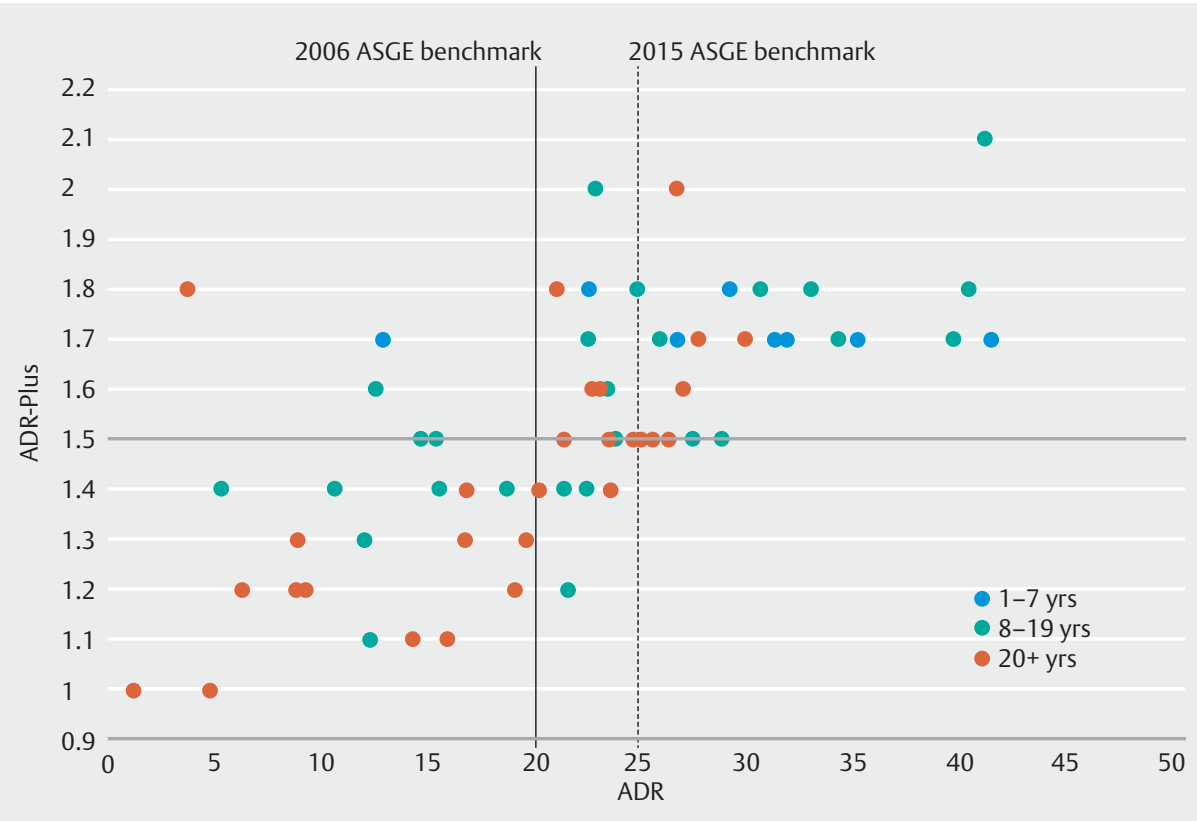

Fig. 2 Plot of adenoma detection rate and adenoma detection rate plus by endoscopists' years since completing residency, New Hampshire Colonoscopy Registry 2009-2014.

were also observed for ADR-plus. ( Supplemental Table 3) For example, endoscopists who completed residency $\geq 20$ years prior to their reference date had significantly lower ADR-plus values relative to those completing their residency in the past 1 to 7 years $(P=0.004)$.

In the plot of ADR versus ADR-plus shown in > Fig. 2, of 69 endoscopists studied, a greater proportion of endoscopists completing their residency $\geq 20$ years prior to the reference date had ADRs $<20 \%$, compared to endoscopists completing residency more recently, but this difference was not statistically significant $(P=0.255)$. Among endoscopists with low ADRs, low ADR-plus values were more common than high ADR-plus values ( $\triangleright$ Fig. 2). Most endoscopists with ADRs $\geq 20 \%$ had high ADR-plus values, although five endoscopists (7.3\%) with ADRs $\geq 20 \%$ had low ADR-plus values. No endoscopists with ADRs $\geq 25 \%$ had low ADR-plus values ( $\triangleright$ Fig. 2 ).

\section{Discussion}

Despite being a preventable disease, CRC remains the second most common cause of death from cancer in the United States [19], thereby creating a compelling argument for improving screening and surveillance. Prevention is possible through detection and removal of polyps at colonoscopy; thus, the national effort to optimize the quality of colonoscopy is key to achieving that goal. Variation in quality of colonoscopy has been well established, leading to widespread efforts to determine appropriate quality indicators $[1,8,11,17,20,21]$. The primary indicator for colonoscopy quality has been the ADR, because higher ADR has been shown to be associated with decreased interval CRC as well as decreased CRC mortality [8,22]. Recognition of the quality of colonoscopy is critical to reducing incidence and mortality from CRC, and accurate quality indicators are essential to that effort.

Recently, several studies have suggested that ADR may not adequately reflect the thoroughness of examination during colonoscopy, and therefore may not be a sufficient quality indicator $[1-3]$. It has been suggested that a "one and done" practice may occur in which, once a likely adenoma has been removed, a less thorough mucosal examination might follow for the rest of the exam $[1-3,23]$. Wang et.al. and others have suggested that ADR may be an inaccurate reflection of the meticulousness of the exam as a result of this type of practice. As a means to address this potential weakness in quality assessment, various methodologies have been suggested to assess the number of adenomas per exam or other metrics, rather than assessment of ADR alone [24,25]. Whether ADR is a reliable quality indicator and whether it accurately reflects significant differences in colonoscopy quality are therefore important questions to examine.

To investigate the potential existence or prevalence of a "one and done" practice, we examined ADR and ADR-plus (screening colonoscopies with $>1$ adenoma) in the statewide NHCR. Similar to other studies, the combination of high ADR but low ADR-plus was considered suggestive of "one and done". Approximately $37 \%$ to $47 \%$ of exams with any adenomas have been shown to have more than one [1]. Based on our investigation of $A D R$ and $A D R$ plus, there was no evidence that the practice of "one and done" was occurring among endoscopists who met or exceeded the 2015 ASGE target (ADR $\geq 25 \%$ ), and only a small proportion (7\%) of endoscopists who met or exceeded the 2006 ASGE ADR target of $20 \%$ had low ADR-plus values suggestive of "one and done". 
The finding that "one and done" is an infrequent practice is reassuring. However, variation in endoscopist ADRs has been well documented and is likely influenced by multiple factors. Previous US studies, including an earlier NHCR investigation [16], have reported a wide range of endoscopist ADRs (from $<10 \%$ to $>50 \%$ ), with substantial differences within endoscopy clinics and health systems $[1,8,11,17,20,21]$. Some variation in endoscopists' ADR is anticipated given different distributions of risk factors within a patient population such as smoking, obesity, sex, and age $[17,18]$. However, even among non-obese patients and non-smokers, the proportion of patients with at least one adenoma typically exceeds $20 \%$ [17] and at least one study has found that differences in patient risk factors do not account for all of the variation in endoscopist ADRs [26].

In our study, most endoscopists with low ADR also had low ADR-plus values, suggesting that these indicators may identify endoscopists who might benefit from education and quality improvement interventions such as improved bowel preparation for their patients. We observed that ADR and ADR-plus decreased monotonically with increasing years since residency, after adjusting for patient risk factors. Technology and new techniques may influence the quality of colonoscopy $[26,27]$. It is possible that endoscopists who have been practicing for longer periods of time might be less likely to use newer-generation endoscopes, although we did not have sufficient information to investigate this hypothesis. Further investigation of the inverse relationship of ADR to endoscopist age is warranted in future studies. Endoscopists completing residency $\geq 20$ years ago did so well before current quality targets were proposed and may not have been trained on methods (e.g. optimal withdrawal time) to achieve high ADRs. This "training by cohort" effect is especially important considering that ADR during training has been shown to predict future ADR [18], and evidence on whether an endoscopist can improve his or her ADR is mixed [29]. For example, tracking and reporting metrics to endoscopists has had variable results in improving ADR or PDRs [21, 30,31 ], although recent evidence has been promising. Two studies have shown an increase in ADR with use of "report cards" [31, 32]. In addition, use of heightened inspection practices (e.g. longer withdrawal times) [33] and leadership training [34] are associated with improved ADRs, and a positive association between continuing medical education credits and ADRs has been observed [26]. Currently, the NHCR sends feedback reports on all colonoscopy quality indicators (including $A D R)$ to participating endoscopists, for use in quality improvement efforts. Further understanding of endoscopist practices and the effectiveness of specific interventions will help to inform efforts aimed at improving ADRs.

The serrated pathway may account for up to $30 \%$ of all CRCs; therefore, inclusion of metrics to assess detection of these types of polyps may also be important for quality assessment [16]. A national benchmark target for serrated detection rate (SDR) has not been established, although endoscopists with ADRs above the $25 \%$ target have been shown to have median SDRs between $7 \%$ and $11 \%$ among screening colonoscopies [16], depending on how the SDR is calculated. (For endoscopists with ADR $>25 \%$, assessing SDR using clinically signifi- cant serrated polyps, the SDR is 7\%. Alternatively, using all proximal serrated polyps, the SDR is $11 \%$ ). When serrated polyps were incorporated into the traditional ADR metric and ADR-plus (to create the SADR and SADR-plus metrics), we observed similar patterns to our main findings: endoscopists with high SADRs had high ADRs as well as high ADR-plus and SADRplus values. For example, among endoscopists with SADR values above the mean, $94.3 \%, 97.1 \%$ and $80.0 \%$ also had ADR, ADR-plus and SADR-plus values at or above mean values, respectively. Although ADR is a component of the SADR, this correlation suggests that endoscopists with high ADRs may have correspondingly high SDRs, because the SADR is a combination of both measures. SADR-plus may also provide insight into an endoscopist's intention to detect any significant polyps. PDR, which incorporates all polyps found, was also strongly correlated with $A D R$, and similarly associated with SADR and ADRplus values. SADR-plus may better reflect the practice of careful endoscopists than PDR since the latter may include insignificant polyps such as $<5 \mathrm{~mm}$ polyps in which the biopsies reveal normal tissue or (diminutive rectosigmoid) hyperplastic polyps.

Our study has several strengths, including the large, population-based sample and diverse endoscopists in multiple community-based settings, and incorporation of multiple patient and endoscopist characteristics in the analyses. In addition, we applied both the 2006 and the 2015 ADR targets to exams to explore characteristics, such as years since residency, of endoscopists who might benefit the most from quality improvement interventions to increase their ADR. We also investigated outcomes using expected sex-specific ADR targets, which reflect real world situations such as Veterans Administration patients who tend to be male smokers, and the gender composition of patient populations, which for several female endoscopists in our study, included $80 \%$ female patients. Our study also had limitations. There is no validated measure of the practice of "one and done"; therefore, we used ADR versus ADR-plus as a proxy measure as suggested by others [1]. In addition, although this study was statewide and reflected endoscopy practices in New Hampshire [35], our findings may not be generalizable to other areas of the country.

\section{Conclusion}

In conclusion, in our large population-based study using the NHCR, the findings suggest that "one and done" is infrequently practiced among endoscopists who meet ADR targets. Most endoscopists with high ADR had a corresponding high ADRplus, suggesting a consistently meticulous approach throughout each colonoscopy, rather than a less careful exam following detection of a likely adenoma, as has previously been suggested. These results support ADR as an appropriate primary measure of quality; the suggestion that alternative metrics looking at the number of adenomas per exam may be critical to assessment of colonoscopy quality was not supported by these findings. Endoscopists who completed their residency decades ago had lower ADR than those completing residency more recently, suggesting that educational efforts and assessments of equipment quality may be a fruitful focus for ADR improve- 
ment. Endoscopists with low ADRs also had low ADR-plus outcomes, suggesting that interventions such as improved bowel preparation could be a useful improvement focus for endoscopists with those outcomes. The results reported here add to our growing understanding of endoscopist practices, which can inform efforts to improve performance and the quality of colorectal cancer screening.

\section{Acknowledgment}

The findings and conclusions in this report are those of the authors and do not necessarily represent the official position of the Department of Veterans Affairs. Funding: The American Cancer Society. The Norris Cotton Cancer Center Developmental Fund. The New Hampshire Colonoscopy Registry has support from the National Cancer Institute, National Institutes of Health (NCI/NIH) (R01CA131141, R21CA191651, HHSN261201400595P), and the Norris Cotton Cancer Center. The New Hampshire State Cancer Registry is supported by the Centers for Disease Control and Prevention's National Program of Cancer Registries (NPCR) through cooperative agreement U58/DP000798 awarded to the New Hampshire Department of Health and Human Services, Division of Public Health Services, Bureau of Public Health Statistics and Informatics, Health Statistics and Data Management Section. The Dartmouth Clinical and Translational Science Institute, under award number UL1TR001086 from the National Center for Advancing Translational Sciences (NCATS) of the National Institutes of Health $(\mathrm{NIH})$.

\section{Competing interests}

Drs Fedewa and Jemal and Ms. Siegel are employed by the ACS, which received a grant from Merck, Inc. for intramural research; however, their salaries are solely funded through ACS funds.

\section{References}

[1] Wang HS, Pisegna J, Modi R et al. Adenoma detection rate is necessary but insufficient for distinguishing high versus low endoscopist performance. Gastrointest Endosc 2013; 77: 71-78

[2] Liem B, Gupta N. Adenoma detection rate: the perfect colonoscopy quality measure or is there more? Transl Gastroenterol Hepatol 2018; 3: 19

[3] Kim SY, Kim HS. Adenoma detection rate: is it the master key for the colonoscopy quality indicator? Transl Gastroenterol Hepatol 2018; 3: 5

[4] Sauer AG, Siegel RL, Jemal A et al. Updated review of prevalence of major risk factors and use of screening tests for cancer in the United States. Cancer Epidemiol Biomarkers Prev 2017; 26: 1192 - 1208

[5] Siegel RL, Miller KD, Jemal A. Cancer Statistics, 2017. CA Cancer J Clin 2017; 67: $7-30$

[6] Anderson JC, Butterly LF. Colonoscopy: quality indicators. Clin TransI Gastroenterol 2015; 6: e77

[7] Rex DK, Petrini JL, Baron TH et al. Quality indicators for colonoscopy. Gastrointest Endosc 2006; 63: S16-28
[8] Corley DA, Jensen CD, Marks AR et al. Adenoma detection rate and risk of colorectal cancer and death. N Engl J Med 2014; 370: 1298 1306

[9] Kaminski MF, Regula J, Kraszewska E et al. Quality indicators for colonoscopy and the risk of interval cancer. N Engl J Med 2010; 362: $1795-1803$

[10] Rex DK, Schoenfeld PS, Cohen J et al. Quality indicators for colonoscopy. Am J Gastroenterol 2015; 110: 72-90

[11] Kahi CJ, Vemulapalli KC, Johnson CS et al. Improving measurement of the adenoma detection rate and adenoma per colonoscopy quality metric: the Indiana University experience. Gastrointest Endosc 2014; 79: $448-454$

[12] Schoenfeld PS, Cohen J. Quality indicators for colorectal cancer screening for colonoscopy. Tech Gastrointest Endosc 2013; 15: $59-68$

[13] Carney PAGM, Butterly LF, Dietrich AJ. The design and development of a population-based colonoscopy registry. J Registry Management 2006; 33: 91 - 99

[14] Greene MA, Butterly LF, Goodrich M et al. Matching colonoscopy and pathology data in population-based registries: development of a novel algorithm and the initial experience of the New Hampshire Colonoscopy Registry. Gastrointest Endosc 2011; 74: $334-340$

[15] Lee YM, Huh KC. Clinical and biological features of interval colorectal cancer. Clin Endosc 2017; 50: $254-260$

[16] Anderson JC, Butterly LF, Weiss JE et al. Providing data for serrated polyp detection rate benchmarks: an analysis of the New Hampshire Colonoscopy Registry. Gastrointest Endosc 2017; 85: 1188-1194

[17] Anderson JC, Weiss JE, Robinson CM et al. Adenoma detection rates for screening colonoscopies in smokers and obese adults: data from the New Hampshire Colonoscopy Registry. J Clin Gastroenterol 2017; 51: e95-e100

[18] Corley DA, Jensen CD, Marks AR et al. Variation of adenoma prevalence by age, sex, race, and colon location in a large population: implications for screening and quality programs. Clin Gastroenterol Hepatol 2013; 11: $172-180$

[19] Siegel RL, Miller KD, Fedewa SA et al. Colorectal cancer statistics, 2017. CA Cancer J Clin 2017; 67: 177- 193

[20] Boroff ES, Gurudu SR, Hentz JG et al. Polyp and adenoma detection rates in the proximal and distal colon. Am J Gastroenterol 2013; 108: $993-999$

[21] Shaukat A, Oancea C, Bond JH et al. Variation in detection of adenomas and polyps by colonoscopy and change over time with a performance improvement program. Clin Gastroenterol Hepatol 2009; 7: $1335-1340$

[22] Kaminski MF, Wieszczy P, Rupinski M et al. Increased rate of adenoma detection associates with reduced risk of colorectal cancer and death. Gastroenterology 2017; 153: $98-105$

[23] Aniwan S, Orkoonsawat P, Viriyautsahakul V et al. The secondary quality indicator to improve prediction of adenoma miss rate apart from adenoma detection rate. Am J Gastroenterol 2016; 111: 723 729

[24] Greenspan M, Rajan KB, Baig A et al. Advanced adenoma detection rate is independent of nonadvanced adenoma detection rate. Am J Gastroenterol 2013; 108: 1286 - 1292

[25] Lee TJ, Rutter MD, Blanks RG et al. Colonoscopy quality measures: experience from the NHS Bowel Cancer Screening Programme. Gut 2012; 61: 1050 - 1057

[26] Adler A, Wegscheider K, Lieberman D et al. Factors determining the quality of screening colonoscopy: a prospective study on adenoma detection rates, from 12,134 examinations (Berlin colonoscopy project 3, BECOP-3). Gut 2013; 62: 236-241

[27] Wallace MB. Improving colorectal adenoma detection: technology or technique? Gastroenterology 2007; 132: 1221 -1223 
[28] van Doorn SC, Klanderman RB, Hazewinkel Y et al. Adenoma detection rate varies greatly during colonoscopy training. Gastrointest Endosc 2015; 82: $122-129$

[29] Corley DA, Jensen CD, Marks AR. Can we improve adenoma detection rates? A systematic review of intervention studies Gastrointest Endosc 2011; 74: 656-665

[30] Sawhney MS, Cury MS, Neeman N et al. Effect of institution-wide policy of colonoscopy withdrawal time $>$ or $=7$ minutes on polyp detection. Gastroenterology 2008; 135: $1892-1898$

[31] Kahi C], Ballard D, Shah AS et al. Impact of a quarterly report card on colonoscopy quality measures. Gastrointest Endosc 2013; 77: 925 931
[32] Keswani RN, Yadlapati R, Gleason KM et al. Physician report cards and implementing standards of practice are both significantly associated with improved screening colonoscopy quality. Am J Gastroenterol 2015; 110: $1134-1139$

[33] Barclay RL, Vicari JJ, Greenlaw RL. Effect of a time-dependent colonoscopic withdrawal protocol on adenoma detection during screening colonoscopy. Clin Gastroenterol Hepatol 2008; 6: 1091 - 1098

[34] Kaminski MF, Anderson J, Valori R et al. Leadership training to improve adenoma detection rate in screening colonoscopy: a randomised trial. Gut 2016; 65: 616-624

[35] US Census Bureau. Demographic and Economic Profiles of New Hampshire's Electorate. 2016: Available at: https://www.census.gov/ newsroom/press-releases/2016/cb16-tps11.html 
- Supplemental Table 1 Definition of quality measures.

\begin{tabular}{|c|c|c|c|}
\hline Name & Description & Numerator & Denominator \\
\hline $\begin{array}{l}\text { Adenoma }{ }^{1} \text { Detection Rate } \\
\text { (ADR) }\end{array}$ & $\begin{array}{l}\text { Proportion of colonoscopies in which at least } \\
1 \text { adenoma was detected }\end{array}$ & $\begin{array}{l}\text { Number of colonoscopies in } \\
\text { which } \geq 1 \text { adenoma }{ }^{1} \text { was found }\end{array}$ & $\begin{array}{l}\text { Number of colonoscopies } \\
\text { performed }\end{array}$ \\
\hline $\begin{array}{l}\text { Serrated and adenoma polyp } \\
\text { detection rate (SADR) }\end{array}$ & $\begin{array}{l}\text { Proportion of colonoscopies in which at least } \\
1 \text { adenoma or Clinically Significant Serrated } \\
\text { Polyp }(\text { CSSP) })^{2} \text { was detected }\end{array}$ & $\begin{array}{l}\text { Number of colonoscopies in } \\
\text { which at least } 1 \text { adenoma or } \\
\text { CSSP was found }\end{array}$ & $\begin{array}{l}\text { Number of colonoscopies } \\
\text { performed }\end{array}$ \\
\hline Polyp detection rate (PDR) & $\begin{array}{l}\text { Proportion of colonoscopies in which at least } \\
\text { one polyp was detected }\end{array}$ & $\begin{array}{l}\text { Number of colonoscopies in } \\
\text { which at least one polyp was } \\
\text { found }\end{array}$ & $\begin{array}{l}\text { Number of colonoscopies } \\
\text { performed }\end{array}$ \\
\hline $\begin{array}{l}\text { Adenoma detection rate } \\
\text { (ADR-Plus) }\end{array}$ & $\begin{array}{l}\text { The average number of adenomas in colo- } \\
\text { noscopies with }>1 \text { adenoma }\end{array}$ & Average number of adenomas & $\begin{array}{l}\text { Colonoscopies with } \\
>1 \text { adenoma }\end{array}$ \\
\hline $\begin{array}{l}\text { Serrated and adenoma polyp } \\
\text { detection rate-plus } \\
\text { (SADR-plus) }\end{array}$ & $\begin{array}{l}\text { The average number of adenomas or CSSP in } \\
\text { colonoscopies with }>1 \text { adenoma }\end{array}$ & Number of adenomas or CSSP & $\begin{array}{l}\text { Colonoscopies with } \\
>1 \text { adenoma }\end{array}$ \\
\hline \multicolumn{4}{|c|}{$\begin{array}{l}\text { CSSP, clinically significant serrated polyp } \\
{ }^{1} \text { Adenoma defined as a polyp including tubular, tubulovillous or villous histological characteristics or CRC with no mention of underlying histology. } \\
{ }^{2} \text { CSSP defined as: CSSP was defined as any sessile serrated adenoma/polyp, traditional serrated adenoma or hyperplastic polyp (HP) }>1 \mathrm{~cm} \text { anywhere in the colon or } \\
\text { an HP }>5 \mathrm{~mm} \text { found in the proximal colon }{ }^{30}\end{array}$} \\
\hline
\end{tabular}

- Supplemental Table 2 Median and interquartile range of colonoscopy quality metrics by endoscopist characteristics, NHCR 20092014.

\begin{tabular}{|l|l|l|}
\hline & Median & $\begin{array}{l}\text { Interquartile } \\
\text { Range }\end{array}$ \\
\hline ADR & 22.9 & $15.9-27.0$ \\
\hline ADR-plus & 1.5 & $1.4-1.7$ \\
\hline SADR & 27.6 & $20.2-33.6$ \\
\hline SADR-plus & 1.5 & $1.3-1.6$ \\
\hline PDR & 40.8 & $28.8-47.9$ \\
\hline
\end{tabular}

NHCR, New Hampshire Colonoscopy Registry; ADR, adenoma detection rate; ADR-plus, adenoma detection rate-plus; SADR, serrated and adenoma polyp detection rate; SADR-plus, serrated and adenoma polyp detection rate-plus; PDR, polyp detection rate 
- Supplemental Table 3 Adjusted generalized linear models predicting adr and adr-plus for each endoscopist characteristic, NHCR 2009-20141,2.

\begin{tabular}{|c|c|c|c|c|c|c|}
\hline & \multicolumn{3}{|l|}{ ADR } & \multicolumn{3}{|c|}{ ADR-Plus } \\
\hline & Beta & SE & $P$ value & Beta & SE & $P$ value \\
\hline Age & & & $P$ for trend $=0.05$ & & & $P$ for trend $=0.06$ \\
\hline $40-49$ & \multicolumn{3}{|c|}{ Reference } & \multicolumn{3}{|c|}{ Reference } \\
\hline $50-59$ & -6.53 & 3.18 & 0.04 & -0.14 & 0.09 & 0.12 \\
\hline $60+$ & -7.85 & 3.72 & 0.04 & -0.20 & 0.10 & 0.05 \\
\hline \multicolumn{7}{|l|}{ Gender } \\
\hline Female & \multicolumn{3}{|c|}{ Reference } & \multicolumn{3}{|c|}{ Reference } \\
\hline Male & -0.42 & 4.08 & 0.99 & -0.08 & 0.11 & 0.46 \\
\hline \multicolumn{7}{|l|}{ Specialty } \\
\hline Gastroenterology & \multicolumn{3}{|c|}{ Reference } & & & \\
\hline Surgery & -8.67 & 2.27 & $<0.001$ & -0.05 & 0.07 & 0.48 \\
\hline Number of years since residency & & & $P$ for trend $=0.02$ & & & $P$ for trend $=0.003$ \\
\hline 1 to 7 & \multicolumn{3}{|c|}{ Reference } & \multicolumn{3}{|c|}{ Reference } \\
\hline 8 to 19 & -5.18 & 3.15 & 0.10 & -0.14 & 0.08 & 0.10 \\
\hline$\geq 20$ & -7.62 & 3.22 & 0.02 & -0.25 & 0.09 & 0.004 \\
\hline \multicolumn{7}{|c|}{$\begin{array}{l}\text { NHCR, New Hampshire Colonoscopy Registry; ADR, adenoma detection rate; SE, standard error } \\
1 \text { 'Four separate models were run for each endoscopist characteristic. All models were adjusted for the proportion of patients that were male, older than } 65 \text { years of } \\
\text { age, obese, former smokers and current smokers. } \\
2 \text { In models, we categorized endoscopists' age }(<40,40-59 \text { and } 60+\text { years), the number of years since residency and number of years since first colonoscopy per- } \\
\text { formed into three groups }(1-7,8-19 \text { and } 20+) \text {. }\end{array}$} \\
\hline
\end{tabular}

